\title{
Predictors of evolution acceptance in a museum population
}

\author{
Lindsay M Barone ${ }^{1 *}$, Andrew J Petto ${ }^{2}$ and Benjamin C Campbell ${ }^{1}$
}

\begin{abstract}
Background: Studies of the U.S. general public have demonstrated that acceptance of evolution is a function of both religion and education. To test if this is true of natural history museum patrons as well, we conducted a survey of visitors to the Milwaukee Public Museum. We hypothesized that education and religion represented separate pathways in the acceptance of evolution. Measures included the MATE scale of evolution acceptance, as well as questions about religious denomination, frequency of religious service attendance, educational attainment and knowledge of evolutionary terms.

Methods: The survey was administered to visitors of the Milwaukee Public Museum during the summer of 2013. A total of 203 museum goers completed the entire survey. We analyzed the data using chi square, analysis of variance, and general linear models.

Results: We found that, on average, museum patrons scored high on acceptance of evolution. Religious denomination or frequency of church attendance was not related to educational attainment. In bivariate analyses, Christian affiliation was associated with lower acceptance of evolution, with nondenominational Christians showing the lowest level of acceptance. Educational attainment, but not religious denomination was related to knowledge of evolutionary terms. In a multivariate model, knowledge of evolutionary terms was predicted by education and religious denomination. In a similar model, acceptance of evolution was predicted by education, religious denomination, frequency of church attendance and knowledge of evolutionary terms.

Conclusion: Our results are consistent with previous findings in U.S. samples demonstrating that religious denomination, religiosity and education are predictors of evolutionary acceptance among adults. In addition, they confirm our hypothesis that religion and education represent largely distinct pathways in the acceptance of evolution. The major impact of religious denomination is on the acceptance, not knowledge of evolution. These results focus attention on understanding what processes allow religious fundamentalists to block the conversion of knowledge about evolution into evolutionary acceptance.
\end{abstract}

Keywords: Religion; Education; Acceptance of evolution; Museums

\section{Background}

More than 150 years after its emergence in Darwin's The Origin of Species, evolution by natural selection remains a controversial topic in the United States, particularly in comparison to other highly educated and technologically developed nations. In fact, acceptance of evolution, one of the foundations of modern science, is lower in the U.S. than in all but one of 34 industrialized countries (Miller et al. 2006). Such widespread rejection of evolution in the U.S. has generally been attributed to the impact of religion

\footnotetext{
* Correspondence: Imbarone@uwm.edu

'Department of Anthropology, University of Wisconsin-Milwaukee, Sabin Hall 290, PO Box 413, Milwaukee, WI 53201, USA

Full list of author information is available at the end of the article
}

(see Coyne 2012), but the international evidence suggests that other factors contribute as well. Across countries, acceptance of evolution has been connected to levels of education and economic development as well as level of religiosity (defined as the importance of religion in one's daily life) (Heddy and Nadelson 2012). However, neither Coyne (2012) nor Heddy and Nadelson (2012) include multivariate analyses that separate economic and religious factors leaving the independent role of religion unclear.

Within the U.S. itself, public acceptance of has been related to religiosity (negatively) as well as education (positively) in multivariate analyses (Heddy and Nadelson 2013, Mazur 2004). Heddy and Nadelson (2013) reported that

\section{实}


variation in acceptance of evolution across states was independently predicted by three variables: high school completion, college attendance, and religiosity. Importantly, variation in GDP per capita by state was significantly related to religiosity (negatively), educational attainment (positively), and evolution acceptance (positively). Yet, state GDP per capita was not an independent predictor of acceptance of evolution in the multivariate model. In other words, economic development appears to influence the acceptance of evolution through its association with education and religiosity, at least within the relatively narrow range of economic development represented by state-level differences within the United States.

Mazur (2004) reported similar findings at the national level, using individual level, rather than aggregate, data. Based on a single question from the 1992, 1993 and 2000 general social survey (GSS), acceptance of evolution was negatively related to fundamentalist religious affiliation and political conservatism and positively related to educational attainment. In contrast, regional differences, urban/rural residence, and dogmatism were not significant predictors of acceptance of evolution. When viewed together, the results from Mazur (2004) and Heddy and Nadelson (2013) provide clear evidence that both religion and education play a significant role in the acceptance of evolution among the U.S. general public and need to be considered in tandem.

The pathway by which education is associated with greater acceptance of evolution seems obvious. Education is expected to increase knowledge of evolution, which in turn should lead to greater acceptance. A variety of studies of students supports this pathway (Lombrozo et al. 2008, Nadelson and Sinatra 2009, Nadelson and Southerland 2010), while simultaneously suggesting that the effect of education on evolution acceptance is relatively weak.

The education pathway is complicated by the evidence which suggests that people may be very knowledgeable about evolution while simultaneously rejecting the science and thus registering a low level of evolution acceptance. Mayrl and Uecker (2011) have argued that the reason why education may have less of an impact on evolution acceptance than expected is that many individuals with creationist beliefs who attain high levels of education (even within the sciences) maintain close social ties with individuals who share their creationist belief structures.

The second pathway, by which religion independently leads to reduced acceptance of evolution, could operate in two ways, either by reduced exposure to evolution or by reducing an individual's susceptibility to evolutionary knowledge. For instance, Hawley et al. (2011) find that among Kansas undergraduates both religious/political conservatism and creationist reasoning are negatively related to exposure to evolution. However, Lombrozo et al. (2008) report that among UC-Berkeley undergraduates, religiosity is negatively and significantly related to acceptance of evolution, but not to knowledge of or attitudes about science. Thus religious involvement may affect acceptance of evolution directly or through an effect on knowledge of evolution.

Figure 1 represents the proposed pathways by which education and religious affiliation may influence acceptance of evolution independently. One pathway starts with education and leads to knowledge about evolution which in turn is associated with a greater acceptance of evolution. In addition, education may influence evolution acceptance indirectly by creating a context in which knowledge of evolution is interpreted positively. The other pathway starts with religious affiliation, which may promote exposure to religious teachings and in turn result in a lower level of evolution acceptance. Additionally, religious involvement may lead to exposure to church teachings which directly contradict evolution, resulting in decreased acceptance of evolution.

It is important to note that our proposed pathways are not meant as exclusive influences on evolution acceptance. While the project we have developed examines education and religion-related pathways (in what could be termed a "sociocultural pathway model"), other factors have been suggested to play a role in acceptance of evolutionary theory. In particular, Evans and Lane (2011) propose that creationist reasoning and evolutionary understanding are best considered jointly as a function of intuitive and analytic beliefs. Furthermore, it has been suggested that factors such as feeling of certainty (Ha et al. 2012) and suspicion of science (Eve et al. 2004) are important in one's willingness to embrace evolution. These distinctions between external influences (such as education and religion) and internal influences (personal beliefs and cognitive processes) are meaningful, yet best understood as a complex network of interconnected elements which ultimately influence evolution acceptance. The dual pathway sociocultural model we have previously described is primarily concerned with examining the effect of external, sociocultural influences on evolution acceptance.

To determine the validity of these two pathways to acceptance of evolution, we conducted a survey at the Milwaukee Public Museum, an anthropology and natural history museum which sees more than 700,000 visitors annually (Milwaukee Public Museum 2014). While the museum population is not representative of the general public it does provide greater diversity than other populations in which acceptance of evolution has been tested, including college students (Hawley et al. 2011, Lombrozo et al. 2008) and teachers in training (Deniz et al. 2008, Ha et al. 2012).

\section{Methods}

\section{Questionnaire construction}

We developed a two-page questionnaire to administer to visitors at the Milwaukee Public Museum, and IRB 


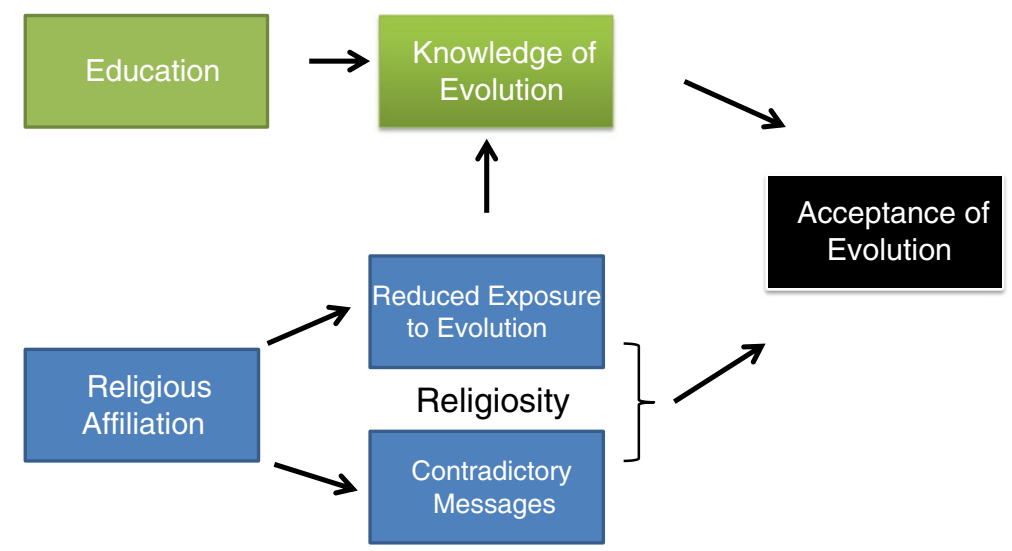

Figure 1 Proposed pathway to evolution acceptance. This diagram suggests that education and religion influence acceptance of by separate pathways. Education by influencing knowledge of evolution, religion by influencing exposure to messages that either reduce exposure to, or directly contradict evolution as a meaningful explanation for life on earth.

approval was obtained through the University of Wisconsin-Milwaukee (protocol no. 13.375). The survey was comprised of basic demographic data including age, sex, and city of residence. Participants were asked to provide their highest degree obtained as well as what that degree focused on, and both degree and major were included in our analysis. In addition, we asked participants to provide us with information about their religious affiliation as well as the frequency with which they attended services or activities as a way of measuring individual religiosity. Two additional questions about whether it was appropriate for the museum to have a human evolution exhibit were also included, including the possibility of an open-ended response. These results of these questions have been reported in Barone and Campbell (2014).

Acceptance of evolutionary theory was assessed by the Measure of the Acceptance of the Theory of Evolution (MATE). The MATE device is a twenty-item Likert-scaled questionnaire developed by Rutledge and Warden (1999) designed to assess attitudes about evolutionary theory. Previous studies of evolution in natural history museums have focused on the understanding of evolutionary knowledge and concepts (Evans et al. 2010, MacFadden et al. 2007, Spiegel et al. 2006), but fewer have emphasized acceptance of evolution on the part of visitors (Growick 2007, Mitchell 2010). This is the first examination of evolution acceptance in the museum context which has employed the MATE.

The MATE was designed to measure personal beliefs about evolution, rather than providing a measurement of knowledge of evolutionary theory. Developed and validated by Rutledge and Warden (1999) in a population of high school biology teachers, the MATE has subsequently been used to study biology teacher acceptance of evolution (Rutledge and Warden 2000, Trani 2004) and has been tested as a tool for use among university students (Rutledge and Warden 2007).

Because the MATE was demonstrated to be a reliable tool for measuring the acceptance of evolution among non-biology major undergraduate students (Rutledge and Warden 2007), we thought the instrument to be potentially useful for measuring evolution acceptance in other populations with a greater range of variation, including levels of education and differing religious backgrounds. Written in language that is similar to what visitors would encounter in label text at the museum, it is not demanding in terms of reading comprehension. Completion takes approximately 5 minutes, creating a time investment for visitors that stopped to complete the survey. We believe this investment of time is one of the issues with using a survey tool like this in a museum setting, and is perhaps the primary reason 77 of our 336 participants did not complete this part of the questionnaire.

As knowledge of evolution and acceptance of evolution are distinct concepts, but may be influenced by similar factors, we also included a section to conduct an assessment of participant's knowledge of evolution. Assessing knowledge in a museum environment can be troublesome, as there are a number of factors at play (Bell et al. 2009) not least of which is the individual's preexisting knowledge (termed the "entrance narrative" by Doering (1999)). Diamond and colleagues (2009) describe the role of recognition in visitor surveys on retention of exhibit content as being similar to that of a multiple-choice test and argue that this style of inquiry is best for an informal educational setting such as a museum.

Given that we were not concerned with a particular museum exhibit and instead were simply examining what visitors to the MPM know, we elected to use a simple term identification task as a measurement of 
recognition and knowledge. This was accomplished by using a matrix of 27 terms commonly taught in an introductory physical anthropology or biology course. The chosen terms included various hominin species names, biological processes, and historical figures. Visitors were asked to place an " $\mathrm{x}$ " next to every term with which they were familiar. However, we did not ask visitors to define the terms with which they were familiar, so this measure does not test a deeper knowledge of evolution. Thus, to be conservative we refer to the measure as "familiarity with evolutionary terms" or "evolutionary familiarity".

\section{Data collection}

The survey was carried out during the summer of 2013 by one of the co-authors (LMB) and a graduate student assistant. Because the ground floor of the Milwaukee Public Museum serves as a cafeteria for the museum as well as the county courthouse, data collection took place on the exhibit floors, thus ensuring that participants were actively visiting the museum. In order to maximize exposure to visitors, data collection alternated between two locations on the exhibit floors. Adult visitors who were not with tour groups (or acting as school chaperones) were approached at random and asked to stop and share their thoughts regarding human evolution and the museum. Upon completion, each survey was dated and given a sequential number as a unique identifier.

\section{Statistical analysis}

Statistical analysis took part in four steps. First, to determine if there were differences in the outcome variables (knowledge of terms and MATE score) across groups for each of the predictor variables, ANOVA models were run. Differences between specific groups were tested using the Bonferroni correction. In the case of a predictor variable with only two categories, a t-test was used. The relationship between the two continuous outcome variables, knowledge of terms and acceptance of evolution was determined based on Pearson's correlation. Chi-square was used to the test the relationship between categorical variables. Next, variables of interest were included as predictors of the two outcome variables in multivariate general linear models (GLM). GLM can accommodate both categorical and continuous variables with continuous variables treated as co-variates. Two different models were estimated. The first predicted the familiarity with evolutionary terms, while the second predicted acceptance of evolution, and included familiarity with terms as a predictor. Finally, to test for internal consistency, Cronbach's alpha was calculated for the study sample.

\section{Results}

\section{Descriptive statistics}

Of the 259 individuals who complete the MATE questions, $54 \%$ were male and $46 \%$ were female. Survey respondents ranged in age from 18 to 80 years of age with only a limited number (9) over the age of 70 years. This was the first visit to the museum for $29 \%$ of those surveyed, and $21 \%$ were members. Respondents were nearly evenly divided between the greater Milwaukee area, the rest of Wisconsin and the rest of the U.S. with only a handful (3) from outside the U.S. Because this survey was focused on acceptance of evolution in the U.S., these three individuals were removed from further analyses.

Descriptive statistics for the variables used to predict acceptance of evolution are shown in Table 1. Religious affiliation was primarily Christian with about equal numbers of Catholics (21\%), Protestants (26\%) and nondenominational Christians (19\%). It is important to note that non-denominational is a common descriptor for many "megachurches", which tend to be fundamentalist in outlook. About as many individuals stated they had no religious affiliation (21\%) as those who said they were Catholic. Other religious groups, including Jews (5), Hindus (2), and Muslims (0) were very sparsely represented. These individuals were placed with those who answered Other (19) in the Other category to avoid small cell sizes.

Respondents reported a wide range of education levels, from those that did not finish school to those with advanced degrees (including $\mathrm{PhD}, \mathrm{JD}, \mathrm{MD}$, and PharmD). Individuals who attended trade schools or specific training courses were placed with those who had some college. The largest group in this sample was individuals with a college education (40\%), followed by those with some college (28\%). Only 159 individuals complete the question about their college concentration, so this variable was not used in the analyses.

Finally, frequency of church attendance ranged from never to more than once a week. However, only one individual reported attending services more than once a week and was reclassified with those who said they attended weekly, creating the category of once a week or more.

In contrast to the predictors, both of our outcome variables are continuous and results are captured in Table 2. The MATE score ranged from 22 to 100, almost the entire 20-100 range. The average was $79.5 \pm 18.0$, suggesting a reasonably high acceptance of evolution over the entire samples. These figures are discussed in more detail in Barone and Buntin (2014). The number of evolutionary terms identified correctly include the entire range from $0-28$, with an average of $17.4 \pm 5.9$. The roughly $60 \%$ correctly identified suggests a somewhat 
Table 1 Descriptive statistics for predictor variables

\begin{tabular}{|c|c|c|}
\hline Variable & Category & Number \\
\hline \multirow[t]{7}{*}{ Age (years) } & $18-29$ & 82 \\
\hline & $30-40$ & 64 \\
\hline & $41-50$ & 53 \\
\hline & $51-60$ & 24 \\
\hline & $61-70$ & 25 \\
\hline & $71-80$ & 9 \\
\hline & Total & 257 \\
\hline \multicolumn{3}{|l|}{ Residence } \\
\hline & Greater Milwaukee & 92 \\
\hline & Rest of Wisconsin & 91 \\
\hline & Other States & 73 \\
\hline & Outside U.S. & 3 \\
\hline & Total & 259 \\
\hline \multicolumn{3}{|l|}{ Education } \\
\hline & Some high school & 4 \\
\hline & HS diploma/GED & 23 \\
\hline & Some college & 72 \\
\hline & College graduate & 102 \\
\hline & Master's degree & 47 \\
\hline & Advanced degree & 10 \\
\hline & Total & 258 \\
\hline \multicolumn{3}{|l|}{ Religion } \\
\hline & Catholic & 44 \\
\hline & Protestant & 55 \\
\hline & Christian & 40 \\
\hline & Other & 26 \\
\hline & None & 44 \\
\hline & Total & 209 \\
\hline \multicolumn{3}{|c|}{ Freq. Church Attendance } \\
\hline & Never & 57 \\
\hline & Rarely & 90 \\
\hline & Monthly & 27 \\
\hline & Weekly & 68 \\
\hline & > Once/week & 12 \\
\hline & Total & 254 \\
\hline
\end{tabular}

Table 2 Descriptive statistics for outcome variables

\begin{tabular}{lllll}
\hline Variable & $\mathbf{N}$ & Mean & Std. deviation & Range \\
\hline $\begin{array}{l}\text { Knowledge of } \\
\text { evolutionary terms }\end{array}$ & 259 & 17.4 & 5.9 & $0-28$ \\
MATE score & 259 & 79.7 & 17.8 & $22-100$ \\
\hline
\end{tabular}

lower familiarity with evolutionary terms than acceptance of evolution.

Because the MATE has not been used previously in the museum context, we tested Cronbach's alpha as a measure of device reliability and internal consistency. For our sample, Cronbach's alpha is .96, indicating strong internal validity. The two previous developmental studies of the MATE among high school teachers (Rutledge and Warden 1999), and university students (Rutledge and Sadler 2007) had similar alpha values (.98 and .94, respectively). This calculation suggests that the MATE, while developed for a formal educational setting, works similarly in informal educational venues.

\section{Predictors of evolutionary familiarity and acceptance of evolution}

Figures 2a-c show the relationship between predictor variables and the MATE score for the predictor variables of interest. MATE scores show a clear difference across religious affiliation $(\mathrm{df}=4,204 ; \mathrm{F}=17.8 ; \mathrm{p}<.0 .001)$. Figure $2 \mathrm{a}$ illustrates that non-denominational Christians in particular show the lowest acceptance of evolution, confirmed by post-hoc group comparison in the ANOVA analysis.

MATE scores show a monotonic increase with education level, as illustrated in Figure $2 \mathrm{~b}(\mathrm{df}=5,252 ; \mathrm{F}=3.85$; $\mathrm{p}=0.002$ ). Post-hoc comparison showed that MATE scores for those with a master's degree were significantly greater than participants with some college $(p=0.030)$. In contrast, MATE scores showed a monotonic decline with the frequency of church attendance, seen in Figure 2c $(\mathrm{df}=4,249 ; \mathrm{F}=17.9 ; \mathrm{p}<0.001)$.

Compared to acceptance of evolution, our measure of evolutionary familiarity showed fewer significant differences with regard to our predictors. Familiarity with evolutionary terms did not differ significantly across religious affiliation (Figure 3a) $(\mathrm{df}=4,204 ; \mathrm{F}=1.81$; $\mathrm{p}=0.13$ ) or frequency of services attended (Figure $3 \mathrm{~b})(\mathrm{df}=4,249$; $\mathrm{F}=2.0 ; \mathrm{p}=0.09$ ). There were no significant post-hoc group differences for either of these two variables. However, familiarity with evolutionary terms did differ across levels of education (Figure $3 \mathrm{c})(\mathrm{df}=5,252 \mathrm{~F}=3.56 \mathrm{P}=0.004)$. Post-hoc groups comparisons show a difference in knowledge of evolutionary terms between those with high school education or equivalent and those with a college degree $(p=0.022)$ or a master's degree $(p=0.02)$. Education levels did not differ by religious affiliation $(\mathrm{df}=208$; $X^{2}=11.0 ; \mathrm{p}=0.95$ ), or by frequency of attending services $\left(d f=253 ; \chi^{2}=16.6 ; p=0.095\right)$. In contrast, frequency of attending services varies significantly by religious affiliation $\left(\mathrm{df}=207 ; \mathrm{X}^{2}=99.54 ; \mathrm{p}<0.001\right)$.

Considering the control variables, none predicted the MATE score; age $(\mathrm{df}=5,251, \mathrm{~F}=0.36 ; \mathrm{p}=0.88)$, sex $(n=250 ; F=1.1 ; p=0.69)$, museum membership $(n=240$; 

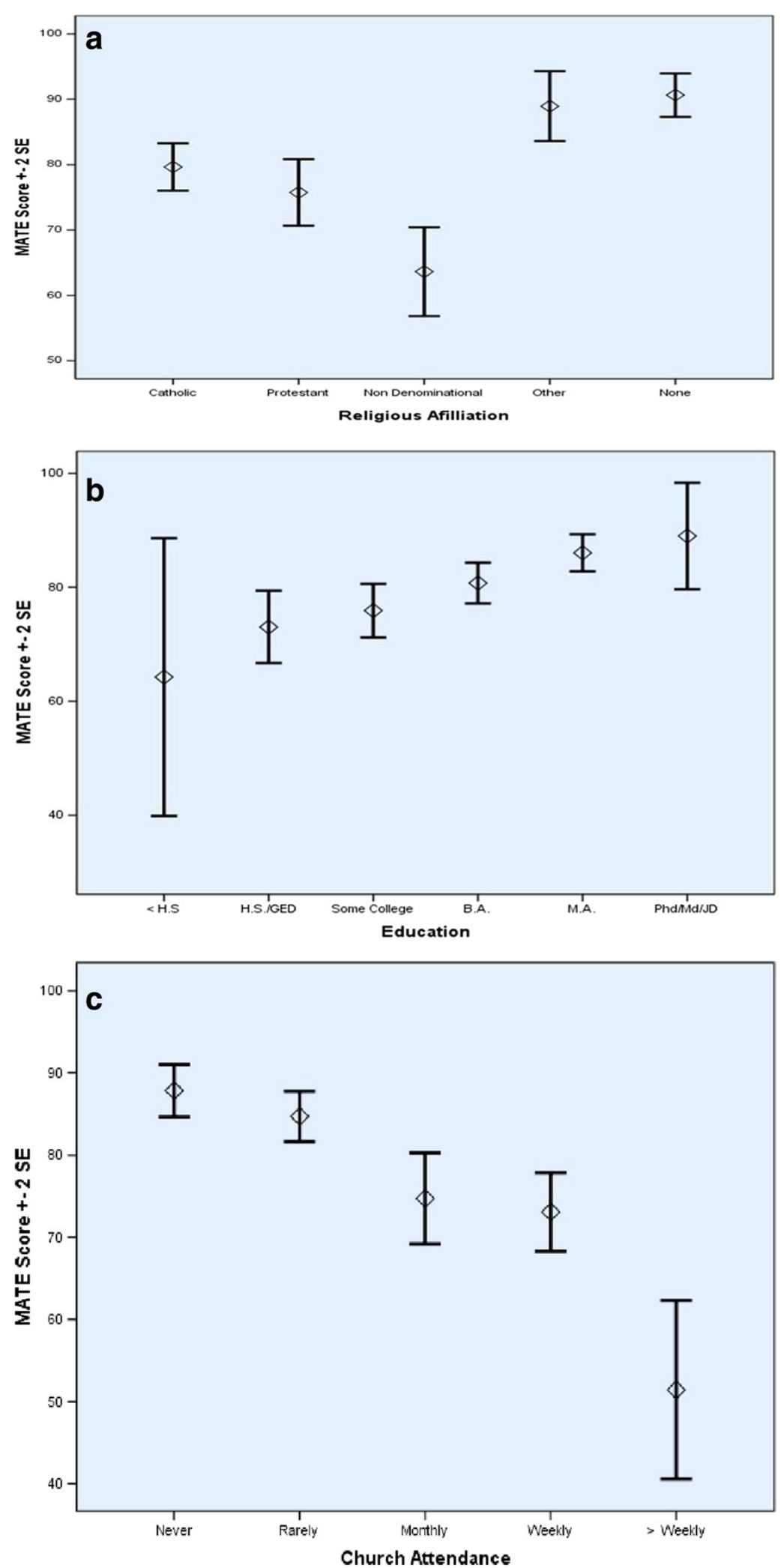

Figure $\mathbf{2}$ (See legend on next page.) 
$\mathrm{F}=0.32 ; \mathrm{p}=0.57)$ and first time visitor to the museum $(\mathrm{n}=254 ; \mathrm{F}=0.21 ; \mathrm{p}=0.65)$. However, MATE scores did show a difference across residence groups ( $\mathrm{df} 2,253 ; \mathrm{F}=$ 3.9; $\mathrm{p}=0.022$ ). Post-hoc contrasts showed that visitors from outside of Wisconsin had a higher acceptance score than those from the Milwaukee area $(p=.009)$ but not compared to those from Wisconsin more generally $(\mathrm{p}=.069)$.

For familiarity with evolutionary terms, age $(\mathrm{df}=5,251$; $\mathrm{F}=0.47 ; \mathrm{p}=0.48)$, sex $(\mathrm{n}=250 ; \mathrm{F}=0.67 ; \mathrm{p}=0.41)$ and whether the individual was a first time visitor to the museum $(\mathrm{n}=255 ; \mathrm{F}=0.61 ; \mathrm{p}=0.44)$ were not significant predictors, while museum membership $(n=240$; $\mathrm{F}=4.29 ; \mathrm{p}=0.04$ ) was. Familiarity with evolutionary terms was not related to residence $(\mathrm{df}=2,249 ; \mathrm{F}=2.0$; $\mathrm{p}=0.09$ ). Knowledge of evolutionary terms and the MATE score were significantly related $(n=259 ; r=0.40$; $\mathrm{p}<0.01)$.

\section{Multivariate predictors of familiarity with evolutionary terms and acceptance of evolution}

The results of the multivariate GLM models for familiarity with evolutionary terms and acceptance of evolution are displayed in Tables 3 and 4, respectively. Education level, religious affiliation, and frequency of attending services were included as predictors of interest, while residence was included as a control. For familiarity with evolutionary terms (Table 3), when all variables are included in the model, $11 \%$ percent of the variance is explained. Education level $(\mathrm{F}=4.01 ; \mathrm{p}=0.002)$ and religious denomination $(\mathrm{f}=2.45 ; \mathrm{p}=0.045)$ are significant independent predictors. Interactions between each of the predictors were tested. None of the interactions were significant, and so none of these was included in the final model.

For acceptance of evolution (Table 4), when education level, religious affiliation, frequency of attending services, and familiarity with evolutionary terms are include in the model $47 \%$ of the variance is explained. All of the variables included, except residence, were highly significant. Again, interactions between each of the predictors were tested. None of the interactions was significant, and none of them was included in the final model.

When the same models for familiarity with evolutionary terms and acceptance of evolution were run recoding religious affiliation into "non-denominational Christians" and "all others", the basic results (not shown) are similar. For familiarity with evolutionary terms, $6 \%$ of the variance was explained, and education level alone was an independent predictor of knowledge of terms. For acceptance of evolution, $47 \%$ of the variance was explained and education level, religious affiliation, frequency of attending services, and knowledge of evolutionary terms were all significant predictors.

\section{Discussion}

The results presented here indicate that religious affiliation, church attendance and educational attainment are predictors of evolutionary acceptance in a museum-going population, consistent with previous findings regarding predictors of evolution acceptance among the U.S. general population (Heddy and Nadelson 2012, Mazur 2004) Previous studies of museum patrons have found that museum visitors tend to be more accepting of evolution than the general public (Spiegel et al. 2006, Stein and Storksdieck 2005), yet even with the high MATE scores (average $=78.5$ ) exhibited in our data (discussed at length in Barone and Buntin 2014), predictors of knowledge and acceptance of evolution are similar to other populations (Heddy and Nadelson 2012, Mazur 2004). Interestingly, both the Heddy and Nadelson (2012) and Mazur (2004) studies of the U.S. general population used variations on a single statement ("Human beings evolved from earlier species of animals".) to determine acceptance of evolution. In contrast, we used the 20 item MATE questionnaire, a multifaceted measure of evolution acceptance. As such our results strengthen the general conclusion that both education and religion play major roles in acceptance of evolution in the U.S.

Furthermore, our results support our hypothesis, outlined in Figure 1, that education and religion represent largely separate pathways in the acceptance of evolution among the U.S. public. Critical to this hypothesis was the finding that religious denomination or frequency of church attendance was not associated with educational attainment. This means that neither factor has an effect on evolutionary knowledge through an association with educational attainment. However, as expected, educational attainment was significantly related to familiarity with evolutionary terms, and familiarity with evolutionary terms was significantly related to acceptance of evolution.

The fact that educational level predicted the MATE score independent of specific knowledge of evolutionary terms suggests that the effects of education on the acceptance of evolution include factors beyond simply knowledge 

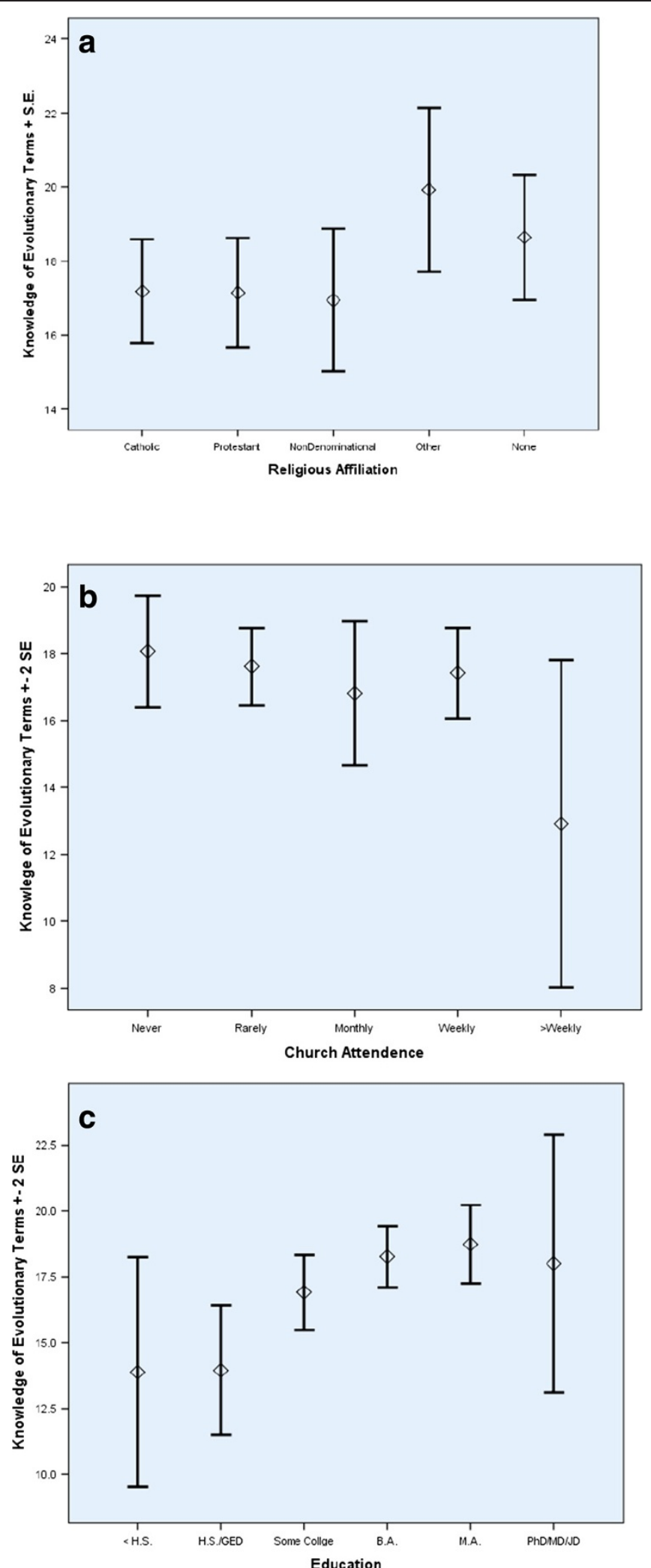

Figure $\mathbf{3}$ (See legend on next page.) 
(See figure on previous page.)

Figure 3 Knowledge of evolutionary terms by major predictors. 3a: Knowledge of Evolutionary Terms by Religious Affiliation. Note the apparent difference between the 3 groups with Christian Affiliations and those without. See text for statistical analysis. $\mathbf{3 b}$ : Knowledge of Evolutionary Terms by Frequency of Church Attendance. Note that group which attends services once or more per week not only have a lower average but a much wider range. See text for statistical analysis. 3c: Knowledge of Evolutionary Terms by Level of Education. Note the general increase in knowledge of evolutionary terms with more education, and the deviation from the trend in the most educated group.

of or familiarity with evolution. It may be best to think of education as indexing exposure to evolution rather than strictly formal learning. For instance, Hawley et al. (2011) found that among a sample of Kansas college students, exposure to evolution outside of the classroom such as visiting natural history museums, reading, or viewing evolution in the popular media is positively related to evolutionary knowledge.

Turning to religion, our results suggest that religious denomination, but not frequency of attending services, does have a slight effect on knowledge of evolutionary terms. Interestingly, this effect did not appear to be driven by the most fundamentalist group in our study, the non-denominational Christians. They showed no significant differences in knowledge of evolutionary terms relative to the other religious denominations in the bivariate analyses. On the other hand, the effect of religious denomination on acceptance of evolution is reflected in the lower MATE scores of Christians vs. non-Christians, but in particular the substantially lower scores on the MATE in the non-denominational Christians relative to all the other religious denominations.

Mazur (2004) points out that Catholicism is a liberal religion with regard to evolution, ever since Pope John Paul II declared evolution compatible with Christian faith in 1996. On the other hand, involvement with fundamentalist Christian religion involves exposure to messages inherently contrary to evolution. In particular for those who believe in the Bible as a source of scientific fact, such as young-earth creationists, evolution is in direct conflict with their beliefs. It would be appear to be among these individuals that knowledge about evolution does not lead to acceptance. In the terms of Evans and Lane (2011) they are not susceptible to the impact of evolutionary knowledge. In fact, while education may increase knowledge of evolution, it may have a polarizing effect on evolutionary

Table 3 Multivariate predictors of outcome variables knowledge of evolutionary terms

\begin{tabular}{lll}
\hline Predictor & $\mathbf{F}$ & $\mathbf{p}$ \\
\hline Residence & 0.61 & 0.54 \\
Education level & 4.09 & 0.007 \\
Religious denomination & 2.45 & 0.045 \\
Freq. services & 1.71 & 0.15 \\
& Model overall adj. $\mathbf{R}^{\mathbf{2}}$ & 0.11 \\
& $\mathbf{N}$ & 203 \\
\hline
\end{tabular}

acceptance, driving such individuals even further into a non-accepting stance on evolution (Baker 2013).

As Hamilton (2011a, 2011b) has pointed out with regard to climate change, the availability of anti-scientific arguments via $\mathrm{TV}$, radio and web, means that those who are ideologically opposed to evolution for religious reasons can find support to maintain their point of view in the face of evidence to the contrary. Unfortunately, our study did not include variables such as creationist thinking that might have allowed us to consider more specifically how religious denominations vary in their ideological stance toward evolution.

\section{Study limitations}

The results presented here have several limitations, most notably in terms of the sample and the simplicity of the measures used. Our sample size is relatively small and represents visitors to the Milwaukee Public Museum, a selected group that does not represent the general public. Our sample is more likely to claim religious affiliation (21\%) than the population of Wisconsin (16\%) (Pew Research Religion and Public Life Project 2013). In addition, the $1.6 \%$ of respondents who reported less than a high school education is substantially lower than the $9.8 \%$ of Wisconsin residents and the $14.3 \%$ of United States residents who reported not completing high school by the age of 25 (United States Census Bureau 2014). However, the Milwaukee Public Museum is not simply a natural history museum, but includes local history as well. Thus patrons are more educated than the general public, but may not be considered exclusively science and/or nature fans.

The MATE itself is not without its shortcomings. Some of the questions are almost too simplistic. For

Table 4 Multivariate predictors of outcome variables MATE score

\begin{tabular}{lll}
\hline Predictor & $\mathbf{F}$ & $\mathbf{p}$ \\
\hline Residence & 2.38 & 0.10 \\
Education level & 3.43 & 0.005 \\
Religious denomination & 8.89 & $<0.001$ \\
Freq. services & 8.01 & $<0.001$ \\
Evol. terms & 12.890 & $<0.001$ \\
& Model overall adj. $\mathbf{R}^{\mathbf{2}}$ & 0.47 \\
& $\mathbf{N}$ & 203 \\
\hline
\end{tabular}


example, item 15 reads "Humans exist today in essentially the same form in which they always have". The scoring instructions make it clear that this item is ostensibly included to identify an individual's belief in special creation. However, for individuals with advanced knowledge of anthropology or biology, this question may present problems as it is dependent on an unclear definition of "human". The response to this question, therefore, is linked to whether the individual is considering simply Homo sapiens or the entire hominin lineage, thus potentially leading to an answer which indicates a belief in special creation rather than acceptance of human evolution.

These faults appear to have minimal impact on our results, but they do suggest that a more extensive instrument of evolutionary acceptance, such as the EALS (Hawley 2011) or the EALS short from (Short and Hawley 2012) can useful in exploring the details of evolutionary acceptance. Whether these rather extensive questionnaires (the long version of the EALS has 104 questions; short version 62) can be effectively employed in a museum context remains to be seen.

Finally, while our measure of evolutionary acceptance is extensive compared to those used in previous studies of the general public, our list of predictors is not extensive. Our study did not include data on political views, adherence to the Bible as a source of scientific information, trust in science, or personality characteristics, all of which have been demonstrated as predictors of evolution acceptance (Hawley et al. 2011, Mazur 2004). Such information would be helpful in understanding whether the effects of fundamentalist religion represent a specific religiously based rejection of evolution or a more general anti-science world view (Gauchat 2008). Indeed, previous studies have indicated that religious rejection of evolution and distrust of the scientific community are linked to one another (Evans 2011, 2013), particularly as a result of the perceived moral and social implications of Darwinian evolution.

\section{Implications and future research}

Our finding that the MATE is a reliable and consistent measure of evolution acceptance can be useful to museum staff in planning, exhibition and programming decisions with their institutions. Vetting the MATE in one museum population provides a clear and relatively simple method that other museums can use to assess how accepting their patrons are of evolution in general. As we noted previously, even the 5 minute time investment in our survey may mean that some museum patrons will not complete the survey. But being aware that the MATE can produce meaningful results should encourage museum staff to invest the time and effort to gather such information.
For instance, such information would allow museum staff to anticipate possible controversies about exhibits about evolution in the planning stage. More specifically, the MATE can be useful in assessing the effectiveness of single programs, displays and exhibits in changing visitors' attitudes towards evolution. Spiegel et al. (2012) concluded, based on 30 adults and 34 children, that a single visit to an evolution exhibit can have a positive impact on individual's understanding of specific evolutionary concepts. A similar before and after design using the MATE would allow for an assessment of changes in general evolutionary attitudes in a larger sample of museum visitors.

Additionally, the successful use of the MATE in an American natural history museum suggests that it can be used to investigation international variation among museum populations. As noted previously, the United States ranks relatively low in evolution acceptance among industrialized countries (Miller et al. 2006). While museum populations tend to be more accepting of evolutionary theory in general, it is unclear how museum populations vary on an international level. Earlier work by Abraham-Silver and Kisiel (2008) indicates that rejection of evolutionary theory is slightly lower among international museumgoers than among Americans. The MATE could easily be used to expand this body of knowledge, giving researchers and educators a glimpse into international variation in evolution acceptance among museumgoers.

\section{Conclusion}

In conclusion our results suggest that the MATE can be effectively employed in informal educational venues such as museums in addition to the more formal education venues where it has been employed in the past. Our results also suggest that both religion and education are fundamentally important predictors of acceptance of evolution in a museum population, consistent with earlier finding for the general public. Collection of additional measures such as exposure to anti-evolution messages, personality traits and political views can help to provide a more complete picture of exactly how these two important factors lead to acceptance or rejection of evolution, particularly in the museum setting.

\section{Competing interests}

The authors declare no competing interests, financial or otherwise.

\section{Authors' contributions}

LMB designed the study, carried out the data collection and helped to write the manuscript. BCC performed the statistical analyses and helped to write the manuscript. AJP helped to write the manuscript. All authors read and approved the final manuscript. 


\section{Acknowledgements}

We thank Maisie Buntin for her work on data collection, as well as Dawn Scher Thomae and Carter Lupton for their help in facilitating data collection. Special thanks to the staff of the Milwaukee Public Museum for providing suggestions and sharing their personal experiences.

\section{Author details}

${ }^{1}$ Department of Anthropology, University of Wisconsin-Milwaukee, Sabin Hall 290, PO Box 413, Milwaukee, WI 53201, USA. ²Department of Biological Sciences, University of Wisconsin-Milwaukee, PO Box 413, Milwaukee, WI 53201, USA

Received: 19 May 2014 Accepted: 9 September 2014 Published online: 09 October 2014

\section{References}

Abraham-Silver, L, \& Kisiel, J. (2008). Comparing visitors' conceptions of evolution: Examining understanding outside the United States. Visitor Studies, $11(1), 41-54$.

Baker, JO. (2013). Acceptance of evolution and support for teaching creationism in public schools: The conditional impact of educational attainment. Journal for the Scientific Study of Religion, 52(1), 216-228.

Barone, L, \& Buntin, M. (2014). Human evolution acceptance among visitors to the Milwaukee Public Museum. Informal Learning Review, 124, 9-13.

Barone, LM, \& Campbell, BC. (2014). Visitor opinions of human evolution in the Milwaukee Public Museum. Museums and Social Issues, 9(2), 1-10.

Bell, P, Lewenstein, B, Shouse, AW, \& Feder, MA. (2009). Learning science in informal environments: People, places, and pursuits. Washington, DC: National Academies Press

Coyne, J. (2012). Science, religion and society: The problem of evolution in America. Evolution, 66(8), 2654-2663.

Deniz, H, Donnelly, LA, \& Yilmaz, I. (2008). Exploring the factors related to acceptance of evolutionary theory among Turkish preservice biology teachers: toward a more informative conceptual ecology for biological evolution. Journal of Research in Science Teaching, 45(4), 420-443.

Diamond, J, Luke, JJ, \& Uttal, DH. (2009). Practical evaluation guide: Tools for museums and other informal educational settings. Plymouth: AltaMira Press.

Doering, ZD. (1999). Strangers, guests, or clients? Visitor experiences in museums. Curator, 42(2), 74-87.

Evans, EM, Spiegel, AN, Gram, W, Frazier, BN, Tare, M, Thompson, S, \& Diamond, J. (2010). A conceptual guide to natural history museum visitors' understanding of evolution. Journal of Research in Science Teaching, 47(3), 326-353

Evans, EM, \& Lane, JD. (2011). Contradictory or complementary? Creationist and evolutionist explanations of the origin(s) of species. Human Development, 54, 144-159.

Evans, JH. (2011). Epistemological and moral conflict between religion and science. Journal for the Scientific Study of Religion, 50(4), 707-727.

Evans, JH. (2013). The growing social and moral conflict between conservative Protestantism and science. Journal for the Scientific Study of Religion, 52(2), 368-385.

Gauchat, GW. (2008). A test of 3 theories of anti-science attitudes. Sociological Focus, 41(4), 337-357.

Growick, D. (2007). Acceptance of evolution and knowledge of related scientific tenets: A survey of science center visitors. Stony Brook, NY: Stony Brook University: M.S.Thesis

Ha, M, Haurty, DL, \& Nehm, RH. (2012). Feeling of certainty: uncovering a missing link between knowledge and acceptance of evolution. Journal of Research in Science Teaching, 49(1), 95-121.

Hamilton, LC. (2011a). Education, politics and opinions about climate change: evidence for interaction effects. Climatic Change, 104(2), 231-242.

Hamilton, LC. (2011b). Climate change: Partisanship, understanding, and public opinion. Carsey Institute Issue Brief, 26, 1-6.

Harrold, F, Eve, R, \& Taylor, J. (2004). Creationism, American-style. In S Coleman \& L Carlin (Eds.), The cultures of creationism (pp. 67-84). Aldershot: Ashgate Publishing.

Hawley, PH, Short, SD, McCune, LA, Osman, MR, \& Little, TD. (2011). What's the matter with Kansas? The development and confirmation of the evolutionary attitudes and literacy survey (EALS). Evolution: Education and Outreach, 4(1), 117-132.
Heddy, BC, \& Nadelson, LS. (2012). A global perspective of the variables associated with acceptance of evolution. Evolution: Education and Outreach 5(3), 412-418

Heddy, BC, \& Nadelson, LS. (2013). The variables related to public acceptance of evolution in the United States. Evolution: Education and Outreach, 6(3).

Lombrozo, T, Thanuku, A, \& Weisberg, M. (2008). The importance of understanding the nature of science for accepting evolution. Evolution: Education and Outreach, 1(3), 290-298.

MacFadden, BJ, Dunckel, BA, Ellis, S, Dierking, LD, Abraham-Silver, L, Kisiel, J, \& Koke, J. (2007). Natural history museum visitors' understanding of evolution. Bioscience, 57(10), 875-882.

Mayrl, D, \& Uecker, J. (2011). Higher education and religious liberalization among young adults. Social Forces, 90(1), 181-208.

Mazur, A. (2004). Believers and disbelievers in evolution. Politics and Life Science, 23(2), 55-61.

Miller, JD, Scott, EC, \& Okamoto, S. (2006). Public acceptance of evolution. Science, 313(5788), 765-766.

Milwaukee Public Museum. (2014). About MPM. http://www.mpm.edu/joinsupport/about-mpm. Accessed 7 May 2014.

Mitchell, C. (2010). Exhibiting human evolution: How identity and ideology get factored into displays at a natural history museum. Amherst, MA: University of Massachusetts-Amherst: M.S.Thesis

Nadelson, LS, \& Sinatra, GM. (2009). Educational professionals' knowledge and acceptance of evolution. Evolutionary Psychology, 7(4), 490-516.

Nadelson, LS, \& Southerland, S. (2010). Examining the interaction of acceptance and understanding: how does the relationship change with a focus on macroevolution. Evolution Education and Outreach, 3, 82-88.

Pew Research Religion and Public Life Project. (2013). Religious landscape survey. http://religions.pewforum.org/maps. Accessed 8 May 2014.

Rutledge, ML, \& Sadler, KC. (2007). Reliability of the Measure of Acceptance of the Theory of Evolution (MATE) instrument with university students. American Biology Teacher, 69(6), 332-335.

Rutledge, ML, \& Warden, MA. (1999). The development and validation of the measure of acceptance of the theory of evolution instrument. School Science and Mathematics, 99(1), 13-18.

Rutledge, ML, \& Warden, MA. (2000). Evolutionary theory, the nature of science, and high school biology teachers: Critical relationships. The American Biology Teacher, 62(1), 23-31.

Short, SD, \& Hawley, PH. (2012). Evolutionary attitudes and literacy survey (EALS): development and validation of a short form. Evolution Education and Outreach, 5, 419-428.

Spiegel, AN, Evans, EM, Gram, W, \& Diamond, J. (2006). Museum visitors' understanding of evolution. Museums and Social Issues, 1(1), 69-85.

Spiegel, A, Evans, EM, Frazier, BF, Hazel, A, Tare, M, Gram, W, \& Diamond, J. (2012). Changing museum visitors' concepts of evolution. Evolution: Education and Outreach, 5, 43-61.

Stein, JK, \& Storksdieck, M. (2005). Life changes museum visitor survey: Summary of results. Annapolis, MD: Institute for Learning Innovation.

Trani, R. (2004). I won't teach evolution; It's against my religion. And now for the rest of the story. The American Biology Teacher, 66(6), 419-427.

United States Census Bureau. (2014). Wisconsin quick facts. http://quickfacts. census.gov/qfd/states/55000.html. Accessed 30 July 2014.

doi:10.1186/s12052-014-0023-2

Cite this article as: Barone et al:: Predictors of evolution acceptance in a museum population. Evolution: Education and Outreach 2014 7:23. 